\title{
Characterization of an azo-dye-degrading white rot fungus isolated from Malaysia
}

\author{
Cheng WN ${ }^{1}$, Sim HK ${ }^{1}$, Ahmad SA ${ }^{1}$, Syed MA ${ }^{1}$, Shukor MY ${ }^{1}$ and Yusof MT ${ }^{2 *}$ \\ ${ }^{I}$ Department of Biochemistry, Faculty of Biotechnology and Biomolecular Sciences, Universiti Putra Malaysia, UPM \\ 43400 Serdang, Selangor, Malaysia. \\ ${ }^{2}$ Department of Microbiology, Faculty of Biotechnology and Biomolecular Sciences, Universiti Putra Malaysia, UPM \\ 43400 Serdang, Selangor, Malaysia.
}

Cheng WN, Sim HK, Ahmad SA, Syed MA, Shukor MY, Yusof MT 2016 - Characterization of an az0-dye-degrading white rot fungus isolated from Malaysia. Mycosphere 7(5), 560-569, Doi $10.5943 /$ mycosphere/7/5/3

\begin{abstract}
Sixty-three local white-rot fungi were isolated from soil and wood samples on potato dextrose agar (PDA). All these isolates were screened for their ability to degrade 4 textile azo dyes; Ponceau 2R (C.I. 16450), Orange G (C.I. 16230), Direct Blue 71 (C.I. 34140) and Biebrich Scarlet (C.I. 26905). Out of 40 isolates that gave positive results, only 1 promising isolate which completely degrades all 4 dyes in the minimum amount of time was selected for further investigation. This isolate was sourced from University Putra Malaysia (UPM) Serdang campus. The isolate was tentatively identified as Coriolopsis sp. Strain arf5 based on the analysis of the internal transcribed spacer (ITS) region. Nutritional studies on defined solid medium showed that this isolate was only able to degrade the 4 azo dyes under nitrogen-limiting conditions and an additional carbon source (glucose) need to be added to provide sufficient energy for the degradation to occur. Various parameters were optimized.
\end{abstract}

Key words - Azo dye - biodegradation - Coriolopsis sp. - white rot fungus

\section{Introduction}

The modern world use synthetic dyes to replace natural dyes, especially in textile industry. However the present of synthetic dyes give rise to a new set of problems. The most obvious problem is aesthetic pollution of water ways caused by the presence of dyes leached from textile factories since they are visible even at low concentrations (Banat et al. 1996). In addition, the presence of dyes could also potentially reduce the amount of sunlight reaching the bottom of rivers and lakes and thus affects the ability of aquatic plants to carry out photosynthesis (Banat et al. 1996, Torres et al. 2003, Wesenberg et al. 2003). This affects the availability of oxygen in the water to other aquatic organisms (Yesilada et al. 2003). They also produce potentially carcinogenic aromatic compound from partial cleavage of azoic dye groups. Current azo dye removal methods usually involve physical and/or chemical treatments. These methods have many disadvantages. Chemical treatments produce large amount of chemical sludge which poses disposal problems (Supaka et al. 2004). Physical treatments are also very expensive due to the high operating 
expenses to produce and regenerate activated carbon (Shen et al. 1992). For all these reasons, biological treatments such as utilization of biodegradative ability of bacteria and fungi are being investigated as a viable and cost effective alternative. Fungi such as Phanerochaete chrysoporium and Tinctoporia sp., both belonging to the ligninolytic white-rot group, are among the first to demonstrate the ability to degrade azo dyes (Awaluddin et al. 2001). However, most published research, including those that have been done in Malaysia have focused on these temperate species (Awaluddin et al. 2001, Levin et al. 2004) while the rich fungal biodiversity available in Malaysia await investigations.

\section{Materials \& Methods}

\section{Sampling sites}

Sixty-three samples were collected from soil and wood from various locations in Selangor, Kelantan, Terengganu and Perak in Peninsula Malaysia. Samples from soil had soft and fleshy fruiting bodies (mushrooms). Sampling was carried out by scooping out the fruiting bodies with some of the surrounding soil underneath it to obtain the whitish mycelia that are growing in the soil. Wood samples were rotten wood underneath and surrounding the fruiting bodies, or pieces of rotten tree bark that were covered with white rot fungal mycelia.

\section{Isolation of fungal isolates}

Collected samples were first washed in tap water, and cut into smaller pieces. For soil samples, only stipes of fruiting bodies and attached mycelia in the soil were used. Cleaned and cut samples were immersed in $5.25 \%$ sodium hypochlorite Clorox ${ }^{\mathrm{TM}}$ for approximately 15 min. Samples were gently shaken to remove excess disinfectant solution before placed on Potato Dextrose Agar (PDA). Once white-rot mycelia (whitish or yellow-brown, flat or cotton-like mycelia radiating out of original sample, with no spore-forming structure) were confirmed, they were cut and subcultured on new PDA plates. This process was repeated until a pure culture was obtained.

\section{Screening for fungal isolates with azo dye-degrading ability}

Screening of isolated white-rot fungal cultures for azo dye-degrading ability was carried out in nitrogen deficient defined medium containing modified Kirk's Basal Medium (KBM) (Tien \& Kirk 1988, Shin et al. 2002) with added azo dye. The full composition of the modified KBM is as follows; $10.1 \mathrm{~g} / \mathrm{L}$ glucose monohydrate, $2 \mathrm{~g} / \mathrm{L}$ L-Asparagine, $0.2 \mathrm{~g} / \mathrm{L} \quad \mathrm{KH}_{2} \mathrm{PO}_{4}, 0.05 \mathrm{~g} / \mathrm{L}$ $\mathrm{MgSO}_{4} .7 \mathrm{H}_{2} \mathrm{O}, 0.01 \mathrm{~g} / \mathrm{L} \mathrm{CaCl}_{2} .2 \mathrm{H}_{2} \mathrm{O}$ and $0.1 \mathrm{ml} / \mathrm{L}$ of stock trace mineral solution. The stock trace elements (TE) solution contains $30 \mathrm{~g} / \mathrm{L} \mathrm{MgSO} 4.7 \mathrm{H}_{2} \mathrm{O}, 10 \mathrm{~g} / \mathrm{L} \mathrm{NaCl}, 5 \mathrm{~g} / \mathrm{L} \mathrm{MnSO} 4 . \mathrm{H}_{2} \mathrm{O}, 1 \mathrm{~g} / \mathrm{L}$ $\mathrm{FeSO}_{4} .7 \mathrm{H}_{2} \mathrm{O}, 1 \mathrm{~g} / \mathrm{L} \mathrm{ZnSO} 4.7 \mathrm{H}_{2} \mathrm{O}, 0.82 \mathrm{~g} / \mathrm{L} \mathrm{CaCl}_{2}, 0.1 \mathrm{~g} / \mathrm{L} \mathrm{CuSO} 4.5 \mathrm{H}_{2} \mathrm{O}, 0.1 \mathrm{~g} / \mathrm{L} \mathrm{NaMoO}_{4} .2 \mathrm{H}_{2} \mathrm{O}$, $0.1 \mathrm{~g} / \mathrm{L} \mathrm{H}_{3} \mathrm{BO}_{3}$ and $1 \mathrm{~g} / \mathrm{L}$ EDTA. For screening purposes, the L-asparagine was omitted to obtain nitrogen deficient condition and replaced with $0.2 \mathrm{~g} / \mathrm{L}$ azo dyes. Four different azo dyes were used for screening, including Ponceau 2R (C.I. 16450; Acid Red 26), Orange G (C.I. 16230; Acid orange 10), Direct Blue 71 (C.I. 34140) and Biebrich Scarlet (C.I. 26905; Acid Red 66). The screening medium was adjusted to $\mathrm{pH} 5.0$, and poured into Petri dishes. The culture plates were observed qualitatively for 21 days for growth and formation of translucent decolourized zones around the growing mycelia which indicates the presence of azo dye-degrading ability.

\section{ITS region sequencing}

DNA was extracted from fresh mycelia grown for 7 days on Potato Dextrose Broth. PCR was performed in a $50 \mu \mathrm{L}$ mix containing $1.5 \mu \mathrm{M}$ of each primer, $200 \mu \mathrm{M}$ of each deoxynucleotide triphosphate, $10 \mathrm{X}$ reaction buffer and $2.5 \mathrm{U}$ of Taq DNA polymerase. The internal transcribe spacer (ITS) region from the genomic DNA was amplified by PCR using the following primers; ITS1-F (5'-CTT GGT CAT TTA GAG GAA GTA A-3') (Gardes \& Brunes 1993) and ITS4 (5'- TCC TCC GCT TAT TGA TAT GC-3') (White et al. 1990). PCR was performed under the following 
conditions: initial denaturation at $94{ }^{\circ} \mathrm{C}$ for $1 \min 25 \mathrm{~s} ; 35$ cycles of $95{ }^{\circ} \mathrm{C}$ for $35 \mathrm{~s}, 55^{\circ} \mathrm{C}$ for $55 \mathrm{~s}$, and $72{ }^{\circ} \mathrm{C}$ for $1 \mathrm{~min}$; and a final extension at $72{ }^{\circ} \mathrm{C}$ for $10 \mathrm{~min}$. Cycle sequencing was subsequently

Table 1 Modified KBM compositions for investigating the effects of carbon and nitrogen limitation on azo dye degradation by Coriolopsis sp. strain arf5.

\begin{tabular}{lccc}
\hline Components & Carbon limitation & Carbon limitation & $\begin{array}{l}\text { Nitrogen } \\
\text { limitation }\end{array}$ \\
\cline { 2 - 4 } & \multicolumn{3}{c}{ Concentration $(\mathbf{g} / \mathrm{L})$} \\
\hline Glucose. $\mathrm{H}_{2} \mathrm{O}$ & 0.0 & 0.0 & 10.1 \\
$\mathrm{KH}_{2} \mathrm{PO}_{4}$ & 0.2 & 0.2 & 0.2 \\
$\mathrm{~L}-\mathrm{Asparagine}$ & 2.0 & 0.0 & 0.0 \\
$\mathrm{NH}_{4} \mathrm{Cl}$ & 0.0 & 2.0 & 0.0 \\
$\mathrm{MgSO}_{4} .7 \mathrm{H}_{2} \mathrm{O}$ & 0.05 & 0.05 & 0.05 \\
$\mathrm{CaCl}_{2} .2 \mathrm{H}_{2} \mathrm{O}$ & 0.01 & 0.01 & 0.01 \\
$\mathrm{TE} \mathrm{solution}$ & $0.1 \mathrm{~mL} / \mathrm{L}$ & $0.1 \mathrm{~mL} / \mathrm{L}$ & $0.1 \mathrm{~mL} / \mathrm{L}$ \\
Azo dye & 0.2 & 0.2 & 0.2 \\
\hline
\end{tabular}

performed with the Big Dye terminator kit (Perkin-Elmer Applied Biosystems) as recommended by the manufacturer. Sequence data were initially recorded and edited using CHROMAS Version 1.45. The resultant 772 bases were compared with the GenBank database using the Blast server at NCBI (http://www.ncbi.nlm.nih.gov/BLAST/). The ITS region sequences for this isolate have been deposited in GenBank under the following accession number EU863194.

\section{Phylogenetic analysis}

A multiple alignment of 20 ITS region sequences closely matches Strain arf5 retrieved from GenBank and aligned using ClustalW (Thompson et al. 1994) with the PHYLIP output option. Alignment positions with gaps were excluded from the calculations. A phylogenetic tree was constructed using PHYLIP, version 3.573 [J. Q. Felsenstein, PHYLIP-phylogeny inference package, version 3.573, Department of Genetics, University of Washington, Seattle, WA (http://evolution.genetics.washington.edu/phylip.html)], with Rhizopus oryzae strain FSU 6022 EU484218 as the outgroup in the cladogram. Evolutionary distance matrices for the neighborjoining/UPGMA method were computed using the DNADIST algorithm program. The program reads in nucleotide sequences and writes an output file containing the distance matrix. The model of nucleotide substitution is from Jukes and Cantor (1969). Phylogenetic tree was inferred by using the neighbor-joining method of Saitou and Nei (1987). With each algorithm, confidence levels for individual branches within the tree were checked by repeating the PHYLIP analysis with 1,000 bootstraps (Felsenstein 1985) by the SEQBOOT program in the PHYLIP package. Majority rule $(50 \%)$ consensus trees were constructed using a family of consensus tree methods called the Ml methods (Margush \& McMorris 1981).

\section{Analysis of carbon and nitrogen limitation on azo dye degradation}

The media used for carbon and nitrogen utilization studies were based on KBM (Shin et al. 2002) with slight modification to suit this study as shown in Table 1 . The 4 azo dyes tested were; Ponceau 2R, Orange G, Direct Blue 71 and Bierich Scarlet. Glucose monohydrate was omitted in the media used for the study on the degradation of azo dyes in carbon-limiting conditions. However, L-asparagine was used as the original nitrogen source and it was known that amino acid could also be the source of carbon for fungi. Therefore, an inorganic nitrogen source, $\mathrm{NH}_{4} \mathrm{Cl}$ was also used in place of L-asparagine. No nitrogen source was added in the medium used to study nitrogen limiting conditions. 


\section{Results and Discussion}

\section{Isolation and screening of fungal isolates}

Sixty-three local white-rot fungi were successfully isolated from 118 samples and cultured on PDA. Out of 63 isolates only 40 isolates showed positive result with varying degree of degradation against the azo dyes tested including Ponceau 2R, Orange G, Direct Blue 71 and Biebrich Scarlet. The highest degree of azo dyes degradation was observed in isolate S17-UPM

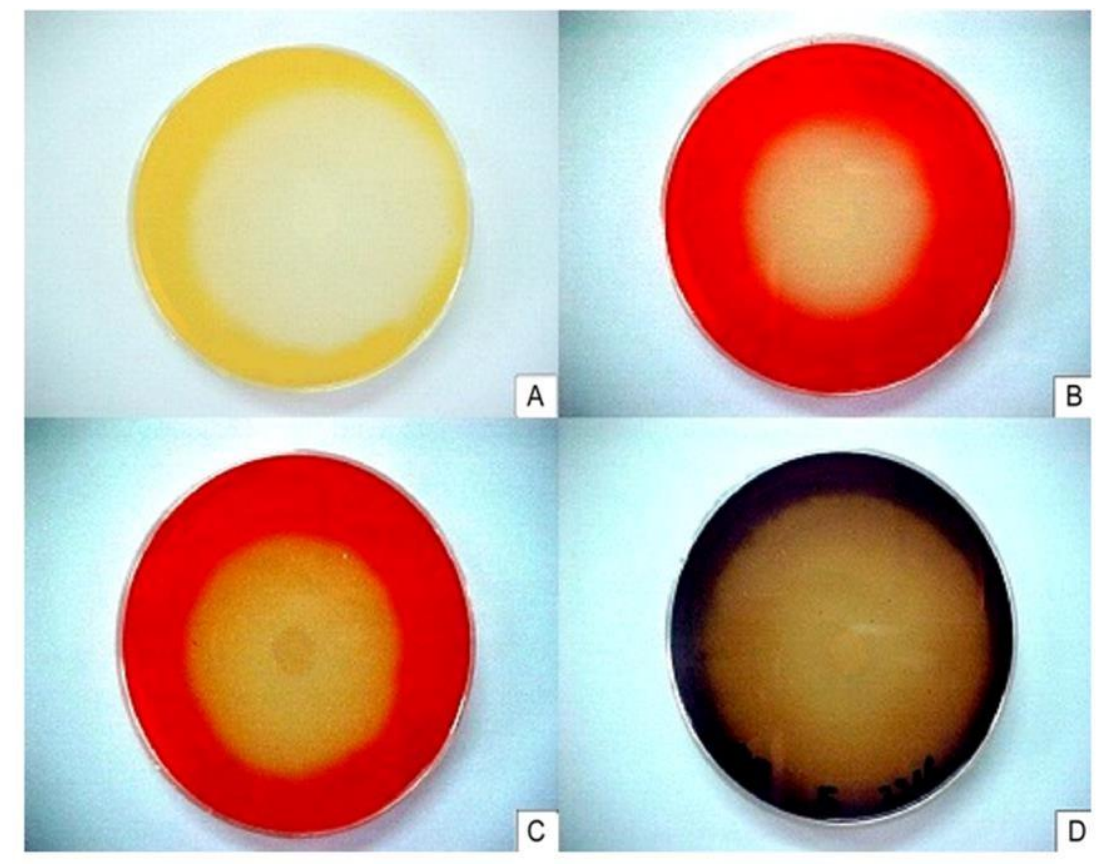

Fig. 1 - Degradation of dyes by Coriolopsis sp. strain arf5 after 7 days of incubation. A. Orange G, B. Ponceau 2R, C. Biebrich Scarlet and D. Direct Blue 71.

which completely degraded Ponceau 2R and Basal Scarlet in 9 days, as well as Orange $\mathrm{G}$ and Direct Blue 71 in 8 days (Fig. 1). This isolate was isolated from Universiti Putra Malaysia, Serdang Campus, Selangor.

\section{Identification of fungal isolates}

Base on ITS analysis, isolate S17-UPM is assigned as Coriolopsis sp. strain arf5. A high bootstrap value $(86.6 \%)$ is seen when Coriolopsis sp. strain arf5 is associated to Coriolopsis polyzona strain Dai9495 and Dai9468 indicating that the phylogenetic relationship between the species is strong (Fig. 2). Most of the reported dye degrading fungi are white rot fungi (Chagas \& Durrant 2001, Selvam et al. 2003, Máximo \& Costa-Ferreira 2004, Novotný et al. 2004, Sathiya et al. 2007, Srinivasan \& Murthy 2009). This feature is probably due to the ability of white rot fungi to degrade a wide range of ligninolytic compounds (Christie 2001).

\section{Effects of carbon limitation and nitrogen limitation on azo dye degradation}

The degree of degradation and the time required for the fungus to degrade the azo dye tested were summarized in Table 2 and 3.It was showed that, no translucent decolourized zones were observed in Coriolopsis sp. strain arf5 culture that was grown on carbon-limiting conditions with Lasparagine or $\mathrm{NH}_{4} \mathrm{Cl}$ as the nitrogen source. The presence of additional nitrogen sources, whether organic or inorganic was shown to repress the ligninolytic system of the white-rot fungi (Zeikus 1981, Wesenberg et al. 2003). We showed that, among the 4 azo dyes tested, Coriolopsis sp. strain arf5 was able to degrade Direct Blue 71 even under nitrogen sufficient conditions, with faster 
degradation rate in the presence of $\mathrm{NH}_{4} \mathrm{Cl}$ as the sole nitrogen source instead of L-asparagine. In contrast, complete or nearly complete degradation of all the azo dyes tested was observed under nitrogen-limiting conditions. Máximo et al. (2003) reported that P. chrysosporium, Ganoderma sp., I. lacteus, P. magnoliea, Rigidoporus sp., T. versicolor and Geotrichum sp. carry out azo dye degradation under nitrogen-limiting conditions while Kapdan et al. (2000) showed nitrogen concentrations determined the decolourization performance of Coriolous versicolor. Nitrogenlimiting conditions are also responsible to trigger the production of ligninolytic enzymes in secondary metabolism (Wesenberg et al. 2003). Under this condition, the azo dyes serve as a source of nitrogen for the fungus.

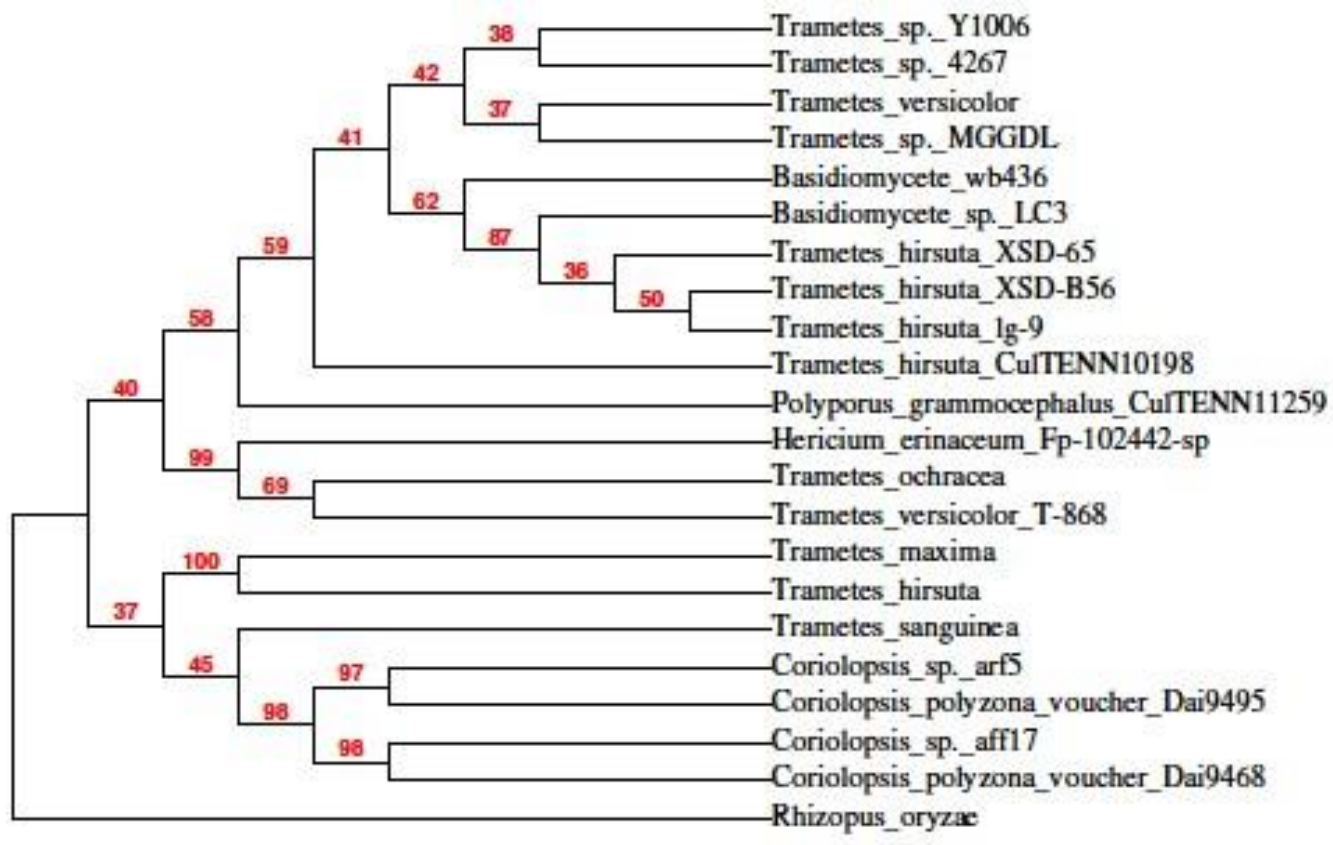

Fig. 2 - A phylogram (neighbor-joining method) showing genetic relationship between Coriolopsis sp. strain arf5 and other related reference fungi based on the ITS region sequence analysis. The numbers at branching points or nodes refer to bootstrap values, based on 1,000 re-samplings. Rhizopus oryzae strain FSU 6022 is the outgroup.

Table 2 Degradation by Coriolopsis sp. strain arf5 in carbon-limiting conditions.

\begin{tabular}{llc}
\hline \multicolumn{1}{c}{ Carbon source } & Nitrogen source & Days \\
\hline Ponceau 2R & L-Asparagine & - \\
& $\mathrm{NH}_{4} \mathrm{Cl}$ & - \\
Orange G & $\mathrm{L}-A$ sparagine & - \\
& $\mathrm{NH}_{4} \mathrm{Cl}$ & - \\
Direct Blue 71 & $\mathrm{L}-\mathrm{Asparagine}$ & $>21$ (incomplete) \\
& $\mathrm{NH}_{4} \mathrm{Cl}$ & - \\
Biebrich & $\mathrm{L}-\mathrm{Asparagine}$ & - \\
Scarlet & $\mathrm{NH}_{4} \mathrm{Cl}$ & (incomplete) \\
\hline
\end{tabular}




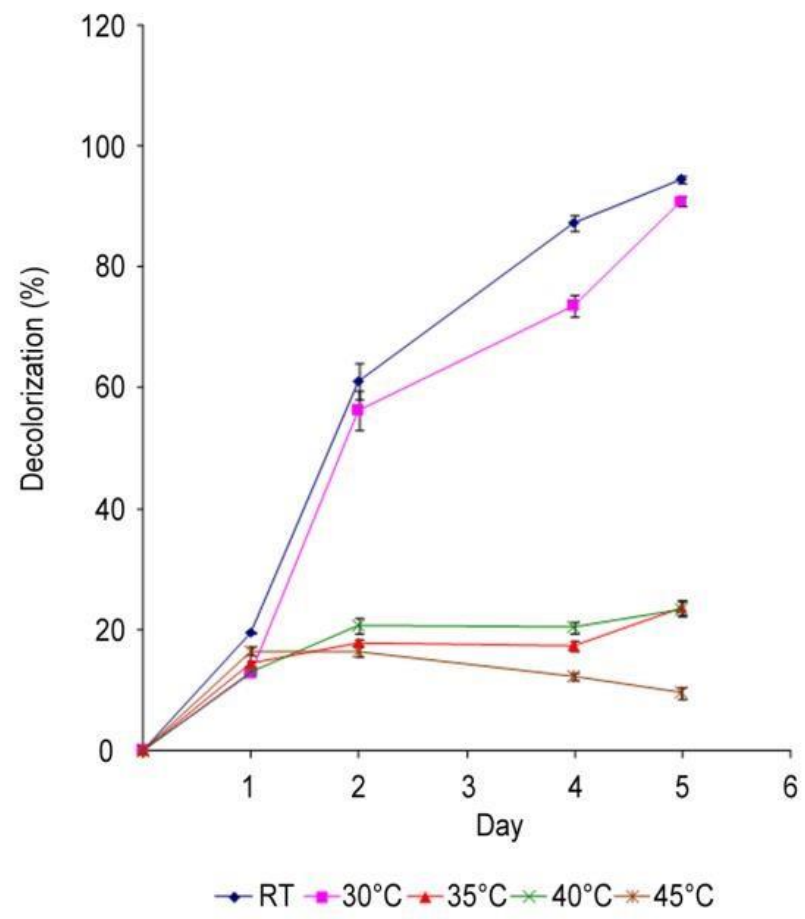

Fig. 3 - Effects of incubation temperatures on Ponceau 2R $(0.2 \mathrm{~g} / \mathrm{L})$ degradation in static cultures. Data collection began after replacement of the spent growth medium with the azo dye-containing degradation medium. Data represent means \pm SEM, $n=3$.

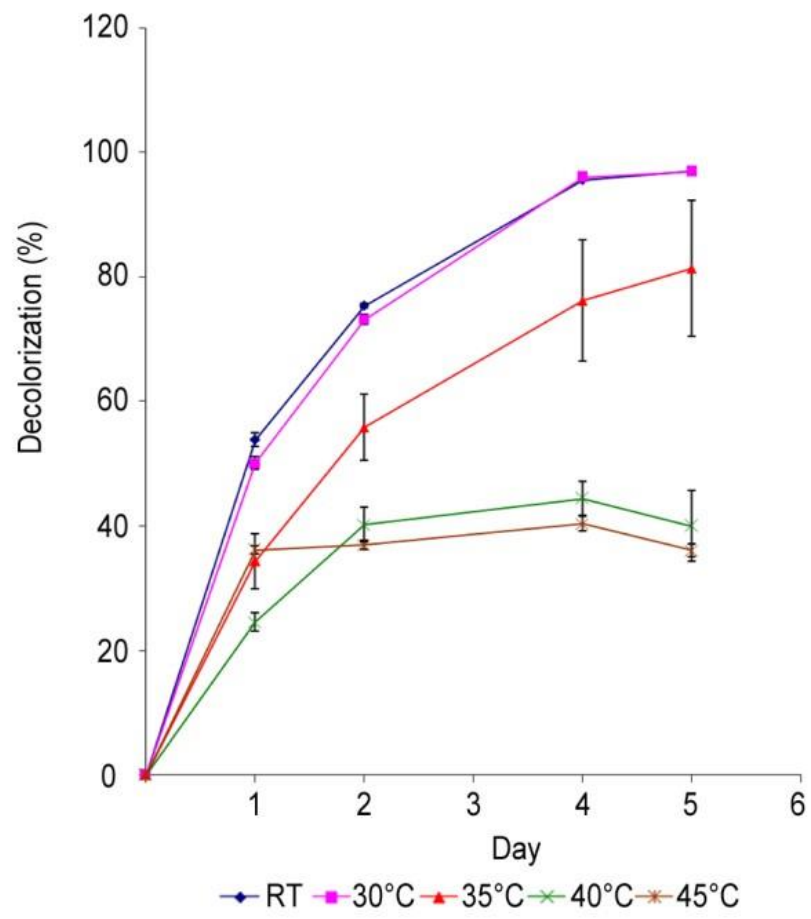

Fig. 4 - Effects of incubation temperatures on Orange G $(0.2 \mathrm{~g} / \mathrm{L})$ degradation in static cultures. Data collection began after replacement of the spent growth medium with the azo dye-containing degradation medium. Data represent means \pm SEM, $n=3$. 


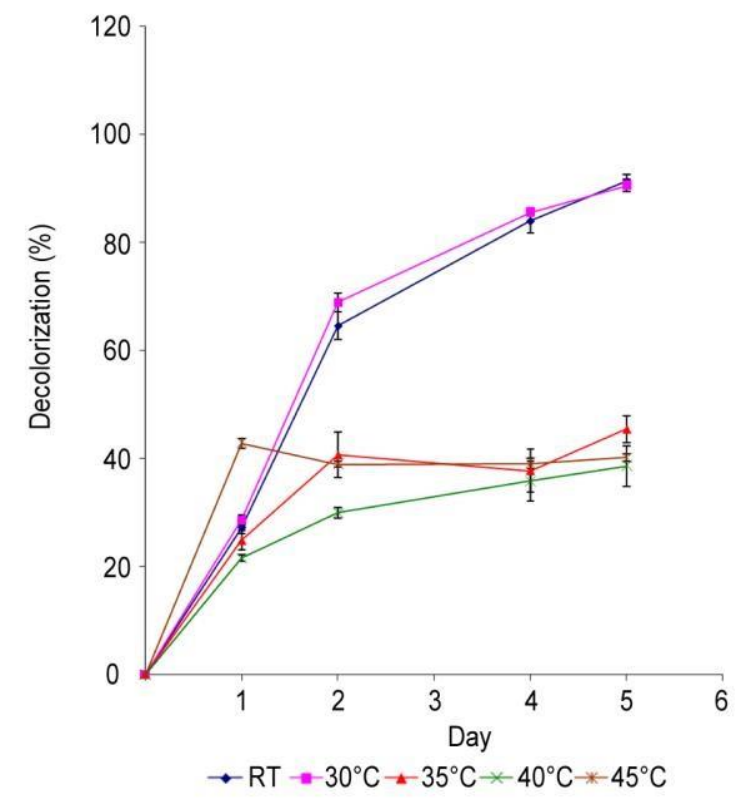

Fig. 5 - Effects of incubation temperatures on Direct Blue $71(0.2 \mathrm{~g} / \mathrm{L})$ degradation in static cultures. Data collection began after replacement of the spent growth medium with the azo dyecontaining degradation medium. Data represent means \pm SEM, $n=3$.

Table 3 Degradation by Coriolopsis sp. strain arf5 in nitrogen-limiting conditions.

\begin{tabular}{clc}
\hline Carbon source & Nitrogen source & Days \\
\hline \multirow{3}{*}{ Glucose } & Ponceau 2R & 10 \\
& Orange G & 7 \\
& Direct Blue 71 & 12 \\
& Biebrich Scarlet & 12
\end{tabular}

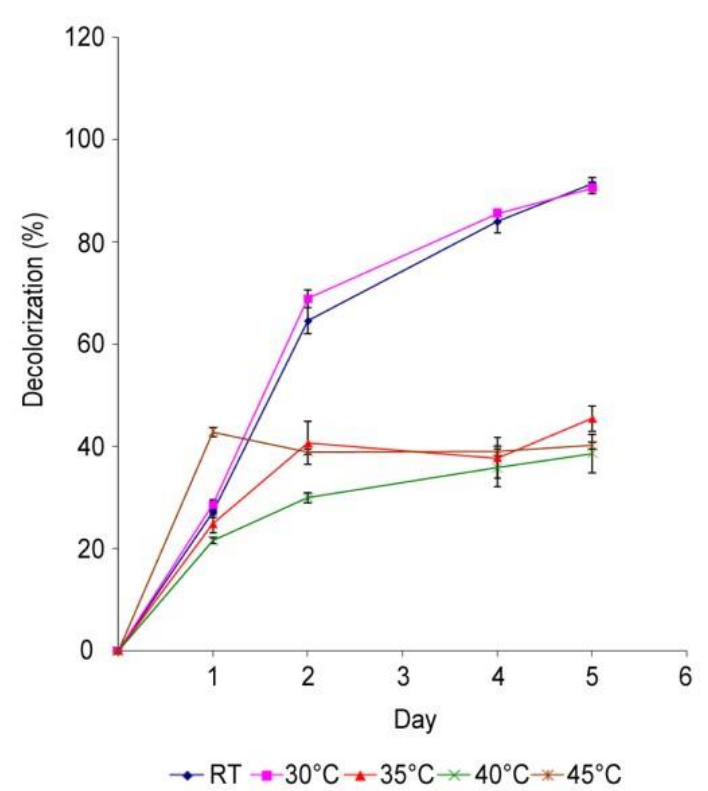

Fig. 6 - Effects of incubation temperatures on Biebrich Scarlet $(0.2 \mathrm{~g} / \mathrm{L})$ degradation in static cultures. Data collection began after replacement of the spent growth medium with the azo dyecontaining degradation medium. Data represent means $\pm S E M, n=3$. 
However, the requirement for nitrogen-limiting conditions is not obligate for all white-rot fungi. Toh et al. (2003) reported an unidentified white-rot fungus isolated from Singapore was able to degrade azo dyes in nitrogen-rich medium with the degradation rates comparable to $P$. chrysosporium. This is not the case for Coriolopsis sp. strain arf5 which is able to grow better in complete medium compared to media supplemented with azo dyes as sole carbon source. This suggests that the 4 azo dyes tested served as poor sources of carbon for growth and Coriolopsis sp. strain arf5 requires additional source of carbon to degrade the azo dyes. This observation adds further evidence to the claim that azo dye degradation occurs during secondary metabolism and that the ligninolytic enzyme system functions optimally when other more readily metabolized carbon sources are available (Zeikus 1981).

\section{Effects of temperature on azo dye degradation}

To determine the optimum temperature for azo dye degradation, Coriolopsis sp. strain arf5 was grown on Ponceau 2R, Orange G and Direct Blue 71 for 48 hours and on Biebrich Scarlet for 96 hours (Fig. 3 to 6). Using one-way ANOVA analysis we showed that the degradation rates of all 4 azo dyes tested were significantly affected by the different incubation temperature $(\mathrm{P}<0.05)$. Coriolopsis sp. strain arf5 have a general azo dye degradation optimum temperature between room temperature to $35^{\circ} \mathrm{C}$. This is similar to the optimum temperature for degrading Solar golden yellow R by Schizophyllum commune IBL-06 (Asgher et al. 2008). Relatively high degradation optimum temperature is potentially advantageous especially in dye effluents treatment because less effort is required to remove the heat produced by the fungi metabolism.

Results from one-way ANOVA showed that Biebrich Scarlet degradation was only slightly affected by the tested temperatures $(\mathrm{P}=0.001)$. Cultures incubated at room temperature, 30, 35, 40 and $45^{\circ} \mathrm{C}$ (Fig. 6) have similar degradation rates where very little degradation occurred with a final decolourization percentage of only $22.24 \%, 24.32 \%, 14.11 \% 14.25 \%$ and $14.35 \%$ at room temperature, $30,35,40$ and $45^{\circ} \mathrm{C}$ respectively. However, this pattern of degradation does not apply to the three other dyes tested although the effects of different incubation temperatures were statistically significant $(\mathrm{P}<0.001)$. The degradation rates are also relatively higher at room temperature and $30^{\circ} \mathrm{C}$ for Orange G, Ponceau $2 \mathrm{R}$ and Direct Blue 71 on day 2 (Fig. 3 to 5). According to results from one-way ANOVA, the various temperatures tested have quite significant effect on all four azo dye degradation especially Ponceau $2 \mathrm{R}$ due to its smallest $\mathrm{P}$ value and highest $\mathrm{R}^{2}$ value $\left(\mathrm{P}<0.0001, \mathrm{R}^{2}=0.9893\right)$.

Based on the $\mathrm{DT}_{50}$ analysis conducted on a series of temperature $\left(30,35\right.$ and $40{ }^{\circ} \mathrm{C}$ ) (Table 4), Coriolopsis sp. strain arf5 was shown to efficiently degrade Orange G followed by Direct Blue 71 and Ponceau 2R. The lowest degradation rate was observed in Biebrich Scarlet which was degraded less than $90 \%$ after 120 hours of incubation.

Table $4 \mathrm{DT}_{50}$ (hours) values of azo dye cultures incubated at various temperatures.

\begin{tabular}{ccccc}
\hline \multirow{2}{*}{ Temperature $\left({ }^{\mathbf{o}} \mathbf{C}\right)$} & P2R & OG & DB71 & BS \\
\hline RT $(27.5)$ & 57.5 & 56.0 & 48.0 & 112.0 \\
30 & 61.3 & 46.7 & 48.0 & 98.6 \\
35 & 51.3 & 29.3 & 34.6 & 69.3 \\
40 & 52.5 & 29.3 & 32.0 & 69.3 \\
45 & $>120$ & 70.6 & 88.0 & $>120$ \\
\hline
\end{tabular}


Table 5 Initial and final degradation medium $\mathrm{pH}$.

\begin{tabular}{ccccc}
\hline Initial pH & Ponceau 2R & Orange G & Direct Blue 71 & $\begin{array}{l}\text { Biebrich } \\
\text { Scarlet }\end{array}$ \\
\hline 4.5 & $3.91 \pm 0.051$ & $4.07 \pm 0.066$ & $4.27 \pm 0.095$ & $4.2 \pm 0.12$ \\
5.0 & $4.24 \pm 0.078$ & $3.96 \pm 0.075$ & $4.24 \pm 0.088$ & $4.18 \pm 0.098$ \\
5.5 & $4.10 \pm 0.068$ & $4.18 \pm 0.079$ & $3.96 \pm 0.082$ & $4.09 \pm 0.15$ \\
5.9 & $4.25 \pm 0.071$ & $4.03 \pm 0.051$ & $4.22 \pm 0.063$ & $4.15 \pm 0.12$ \\
\hline
\end{tabular}

Table $6 \mathrm{DT}_{50}$ (hours) values of azo dye cultures incubated at different initial $\mathrm{pH}$.

\begin{tabular}{ccccc}
\hline & & \multicolumn{3}{c}{ DT50 (Hours) } \\
pH & P2R & OG & DB7 & \\
& 40.0 & 52.6 & 32.6 & BS \\
\hline 4.5 & 53.5 & 50.5 & 43.2 & 65.6 \\
5.0 & 44.4 & 58.5 & 33.7 & 58.9 \\
5.5 & 55.5 & 60.0 & 40.0 & 77.8 \\
5.9 & &
\end{tabular}

\section{Effects of different initial pH on azo dye degradation}

The effects of different initial medium $\mathrm{pH}$ on azo dye degradation by Coriolopsis sp. strain arf5 were investigated. Using one-way ANOVA, we showed that there is no significant difference observed in the degradation of Orange G, Direct Blue 71 and Biebrich Scarlet after 48 hours of incubation $(\mathrm{P}>0.05)$. However, a slight difference in the degradation rate of Ponceau $2 \mathrm{R}(\mathrm{P}<$

0.05 ) was observed. We recorded a slightly higher Ponceau $2 \mathrm{R}$ degradation rate at the initial $\mathrm{pH}$ of 4.5 while the lowest degradation rate was recorded at the initial $\mathrm{pH}$ of 5.0. Even though the initial $\mathrm{pH}$ does not significantly affect the degradation rate of the dyes tested, we showed that the degradation still occurs. This proved that Coriolopsis sp. strain arf5 is able to degrade Orange G, Direct Blue 71, Ponceau 2R and Biebrich Scarlet within a wide range of $\mathrm{pH}$. Previous report by Tekere et al. (2001) has showed that degradation of Poly R478 by T. versicolor, Trametes pocas, Trametes cingulata, Pycnoporus sanguineus and D. concentric was affected by the initial $\mathrm{pH}$ of the media used. Study by Kapdan et al. (2000) also demonstrated that optimum degradation rate of Everzol Turquoise Blue by $C$. versicolor was achieved at $\mathrm{pH} 4.5$.

The final $\mathrm{pH}$ of the medium was recorded after 48 hours of incubation. We showed that the initial $\mathrm{pH}$ of the medium used for the degradation study decrease after 48 hours of incubation (Table 5). This suggests acid was produced during the azo dyes degradation by the fungus. Similar observation was reported by Tekere et al. (2001) in white-rot fungi suggesting that the fungi produced organic acids during secondary metabolism thus causing the gradual reduction of the $\mathrm{pH}$. Another possible explanation is that some fungi are able to use medium buffer such as citratephosphate and tartrate buffers as their alternative carbon source during azo dyes degradation (Swamy \& Ramsay 1999). However, this is not the case for sodium acetate buffer. It was reported that, fungi were unable to utilize sodium acetate buffer as their alternative carbon source (Swamy \& Ramsay 1999).

Based on the $\mathrm{DT}_{50}$ values of Table 6, Direct Blue 71 was the dye that degraded fastest with smallest values for all of the initial $\mathrm{pH}$, followed by Ponceau 2R, Orange $\mathrm{G}$ and Biebrich Scarlet. The uninoculated abiotic controls and killed-mycelia controls did not show significant azo dye degradation.

In conclusion, 63 white-rot fungi were isolated from various locations in Malaysia Peninsular and screened for their ability to degrade the azo dyes; Ponceau 2R, Orange G, Direct 
Blue 71 and Biebrich Scarlet. Out of the 63 fungal isolates, we selected a strain identified as Coriolopsis $s p$. strain arf5 based on its azo dyes degradation rate. We showed the fungus was only able to degrade azo dyes in nitrogen-limiting conditions. This suggests that the fungus is able to utilize azo dyes as sole nitrogen source. The effect of temperature on degradation rate by the fungus is one of the parameter studied. We showed that Coriolopsis sp. strain arf5 was able to degrade azo dyes efficiently between room temperature to $40{ }^{\circ} \mathrm{C}$. This suggests that the fungus has potential for pollution treatment application especially in South East Asia.

Acknowledgements

This work was financed by Fundamental Research Grant Scheme

(FRGS/2/2014/SG05/UPM/02/6), Ministry of Higher Education, Malaysia.

\section{References}

Asgher M, Kausar S, Bhatti HN, Shah SAH, Ali M. 2008 - Optimization of medium for decolorization of Solar golden yellow R direct textile dye by Schizophyllum commune IBL06. International Biodeterioration \& Biodegradation 61, 189-193.

Awaluddin R, Ibrahim D, Omar IC, Manaf UA. 2001 - Decolourization of commercially available synthetic dyes by the white rot fungus, Phanerochaete chrysosporium ME446 (ATCC 34541). NSF Workshop Proceedings, Kuala Lumpur.

Banat IB, Nigam P, Singh D, Marchant R. 1996 - Microbial decolorization of textile-dye containing effluents: a review. Bioresource Technology 58, 217-227.

Chagas EP, Durrant LR. 2001 - Decolorization of azo dyes by Phanerochaete chysosporium and Pleurotus sajor-caju. Enzyme and Microbial Technology 29, 473-477.

Christie R. 2001 - Colour Chemistry. The Royal Society of Chemistry, Cambridge, United Kingdom.

Felsenstein J. 1985 - Confidence limits on phylogenies: An approach using the bootstrap. Evolution 39, 783-791.

Gardes M, Bruns TD. 1993 - ITS primers with enhanced specificity for basidiomycetes application to the identification of mycorrhizae and rusts. Molecular Ecology 2, 113-118

Jukes TH, Cantor CR. 1969 - Evolution of protein molecules. In: Munro HN (Ed) Mammalian protein metabolism, New York: Academic Press, PP 21-123.

Kapdan IK, Kargi F, McMullan G, Marchant R. 2000 - Effect of environmental conditions on biological decolourization of textile dyestuff by $C$. versocolor. Enzyme and Microbial Technology 26, 381-387.

Levin L, Papinutti L, Forchiassin F. 2004 - Evaluation of Argentinean white rot fungi for their ability to produce lignin-modifying enzymes and decolourise industrial dyes. Bioresource Technology 94, 169-176.

Margush T, McMorris FR. 1981 - Consensus n-Trees. Bulletin of Mathematical Biology 43, 239244.

Máximo C, Amorim MTP, Costa-Ferreira M. 2003 - Biotransformation of industrial reactive azo dyes by Geotrichum sp. CCMI 1019. Enzyme and Microbial Technology 32, 145-151.

Máximo C, Costa-Ferreira M. 2004 -Decolourisation of reactive textile dyes by Irpex lacteus and lignin modifying enzymes. Process Biochemistry 39, 1475-1479.

Novotný C, Svobodova K, Kasinath A, Erbanova P. 2004 - Biodegradation of synthetic dyes by Irpex lacteus under various growth conditions. International Biodeterioration \& Biodegradation 54, 215-223.

Page RDM. 1996 - TreeView: an application to display phylogenetic trees on personal computers. Computer Applications in Biosciences 12, 357-358.

Saitou N, Nei M. 1987 - The neighbor-joining method: a new method for reconstructing phylogenetic trees. Molecular Biology Evolution 4, 406-425. 
Sathiya Moorthi P, Periyar Selvam S, Sasikalaveni A, Murugesan K, Kalaichelvan PT. 2007 Decolorization of textile dyes and their effluents using white rot fungi. African Journal of Biotechnology 6, 424-429.

Selvam K, Swaminathan K, Chae KS. 2003 - Decolourization of azo dyes and a dye industry effluent by white rot fungus Thelephora sp. Bioresource Technology 88, 115-119.

Shen HP, Mou D-G, Lim K-K, Feng P, Chen C-H. 1992 - Microbial decolourization of wastewater. United States Patent, Pat. No. 5,091,089.

Shin M, Nguyen T, Ramsay J. 2002 - Evaluation of support materials for the surface immobilization and decolourization of amaranth by Trametes versicolor. Applied Microbial Biotechnology 60, 218-223.

Srinivasan SV, Murthy DV. 2009 - Statistical optimization for decolorization of textile dyes using Trametes versicolor. Journal of Hazardous Material 165, 909-914.

Supaka N, Juntongjin K, Damronglerd S, Delia M-L, Strehaiano P. 2004 - Microbial decolourization of reactive azo dyes in a sequential anaerobic-aerobic system. Chemical Engineering Journal 99, 169-176.

Swamy J, Ramsay JA. 1999 - The evaluation of white rot fungi in the decoloration of textile dyes. Enzyme and Microbial Technology 24, 130-137.

Tekere M, Mswaka AY, Zvauya R, Read JS. 2001 - Growth, dye degradation and ligninolytic activity studies on Zimbabwean white rot fungi. Enzyme and Microbial Technology 28, 420 426.

Thomson JD, Higgins DG, Gibson TJ. 1994 - CLUSTAL W: improving the sensitivity of progressive multiple sequence alignment through sequence weighting, position-specific gap penalties and weight matrix choice. Nucleic Acids Research 22, 4673-4680.

Tien M, Kirk TK. 1988 - Lignin peroxidase of Phanerochaete chrysosporium. Methods in Enzymology 161, 238-248.

Toh Y-C, Yen JJL, Obbard JP, Ting Y-P. 2003 - Decolourazation of azo dyes by white rot fungi (WRF) isolated in Singapore. Enzyme and Microbial Technology 33, 569-575.

Torres E, Bustos-Jaimes I, Le Borgne S. 2003 - Potential use of oxidative enzymes for the detoxification of an organic pollutant. Applied Catalysis B: Environmental 46, 1-15.

Wesenberg D, Kyriakides I, Agathos SN (2003) White rot fungi and their enzymes for the treatment of industrial dye effluents. Biotechnol Adv 22(1-2):161-187

White TJ, Bruns T, Lee S, Taylor J. 1990 - Amplification and direct sequencing of fungal ribosomal RNA genes for phylogenetics. In: Innis MA, Gelfand DH, Sninsky JJ, White TJ (eds) PCR protocols: a guide to methods and applications. New York: Academic Press, PP

315-322.

Yesilada O, Asma D, Cing S. 2003 - Decolourization of textile dyes by fungal pellets. Process Biochemistry 38, 933-938.

Zeikus JG. 1981 - Lignin metabolism and the carbon cycle. Polymer biosynthesis, biodegradation and environmental recalcitrance. Advances Microbial Ecology 5, 211-243. 